\title{
O PARADOXO DO DESENVOLVIMENTO: DIREITO AMBIENTAL E BENS COMUNS NO CAPITALISMO
}

\author{
Maria de Fatima Schumacher Wolkmer \\ Doutora em Direito pela UFSC. Profa. do Programa de Mestrado em Direitos Humanos e Sociedade \\ da UNESC-SC.Integrante do NUPEC - "Núcleo de Estudos em Direitos Humanos e Cidadania" \\ (UNESC). Membro do Projeto de Pesquisa "Em Busca de Novas Gramáticas para os Direitos \\ Humanos: Inovações Sócio-jurídico-políticas na América-latina e África”, Edital Universal CNPq, \\ 2017-2019. Igualmente, do Projeto de Pesquisa "O Comum, os Novos Direitos e os Processos \\ Democráticos Emancipatórios", 2018. \\ E-mail: mfwolkmer@yahoo.com.br
}

Débora Ferrazzo

Doutoranda em Direito pela Universidade Federal do Paraná (UFPR); Mestra em Direito pela
Universidade Federal de Santa Catarina (UFSC). Professora no curso de Direito da Universidade
do Extremo Sul Catarinense (UNESC). Integrante do Núcleo de Estudos e Filosóficos (NEFIL/
UFPR) e do Núcleo de Pesquisas em Desenvolvimento Regional (FURB). Pesquisadora no Grupo
de Pesquisas em Pensamento Jurídico Crítico Latino-americano (UNESC).
E-mail: dferrazzo@hotmail.com.

\section{RESUMO}

Nota-se o estágio avançado do processo de globalização e homogeneização do mundo, que tem no projeto de desenvolvimento global um instrumento estratégico. Todavia, o desenvolvimento é um conceito contraditório, cujos limites são expostos por perspectivas críticas, uma reflexão fundamental, visto ser o discurso desenvolvimentista concebido dentro da lógica capitalista e ter como consequências a tragédia ambiental planetária e o desaparecimento de tradições e culturas periféricas. Projeto industrial e lógica da propriedade, componentes dos discursos de desenvolvimento, impõem-se aos países, redefinindo políticas públicas e ordenamentos jurídicos, bem como incluindo países nas relações mercantis internacionais. O custo desse projeto é elevado, pois tem conduzido à supressão de ecossistemas, uma séria ameaça à biodiversidade. Diante da percepção desse contexto, objetiva-se analisar criticamente o projeto ocidental de desenvolvimento, adotando-se pressupostos metodológicos da ética da 
libertação de revisão histórico-crítica, com os quais espera-se evidenciar a necessidade de descolonizar o conceito de desenvolvimento, tarefa que pode revelar no conceito de bens comuns e em teorizações do comum caminhos de resistência à universalização dos valores capitalistas.

PALAVRAS-CHAVE: desenvolvimento; direito ambiental; bens comuns; descolonização; capitalismo.

\title{
THE PARADOX OF DEVELOPMENT: ENVIRONMENTAL LAW AND COMMON GOODS IN CAPITALISM
}

\begin{abstract}
We can note the advanced stage of the process of globalization and homogenization of the world, which has in the global development project a strategic instrument. However, development is a contradictory concept whose limits are exposed by critical perspectives, a fundamental reflection, since it is the developmental discourse conceived within the capitalist logic and have as consequences the planet environmental tragedy and the disappearance of peripheral traditions and cultures. Industrial design and logic of ownership, components of development discourses, is imposed on countries, redefining public policies and legal systems, as well as including countries in international mercantile relations. The cost of this project is high because it has led to the suppression of ecosystems, a very serious threat to biodiversity. Given the perception of this context, it aims to critically analyze the Western development project, adopting methodological assumptions of the ethics of the liberation of historicalcritical review, with which it is expected to highlight the need to decolonize the concept of development, a task that can reveal in the concept of common goods and in theories of the common paths of resistance to universalize the capitalist values.
\end{abstract}

KEYWORDS: development; environmental law; common goods; decolonization; capitalism. 


\section{INTRODUÇÃO}

A ciência contemporânea é resultado de um processo que a estruturou dentro dos limites de uma racionalidade específica, tributária da tradição cartesiana e concebida num contexto geográfico, temporal, econômico e cultural bem-definido: a modernidade capitalista europeia. A partir dos pressupostos definidos dentro desse horizonte eurocêntrico, constituem-se os paradigmas científicos, políticos e jurídicos que, de fato, "(re)colonizam" as sociedades periféricas e contribuem para a sustentação de uma ideologia em que se "aceita" a superioridade autodeclarada de uma específica sociedade "civilizada". Um desses debates refere-se à questão do desenvolvimento. Um conceito que tem ocupado e, por vezes, determinado a agenda de diversos países. Um conceito importante, visto que impulsiona certas medidas fundamentais para a melhoria da vida de diversos povos e nações, mas um conceito que não deixa de ter sua própria origem monocultural, razão pela qual se propõem algumas reflexões críticas.

Os avanços tecnológicos e do processo de globalização propiciaram a aproximação entre países e nações. Organismos e sistemas internacionais se consolidaram nas últimas décadas, com as mais distintas nações assumindo projetos comuns. O desenvolvimento é um dos conceitos que orienta tais projetos, fundado no discurso de solidariedade global e combate à miséria e sofrimento humano, de modo que se pode dizer que atualmente o desenvolvimento é um dos maiores projetos da humanidade. Nota-se, ao analisar a questão, que, apesar das tentativas de democratização e humanização da ideia, o desenvolvimento limita-se à concepção identificada com o projeto civilizatório da modernidade ocidental, por meio do qual se buscam garantir mantidas pautas como crescimento econômico, industrialização, desenvolvimento científico, entre outros. Ou seja, trata-se de um projeto que reconhece apenas o desenvolvimento compatível com os valores e cânones da sociedade ocidental capitalista e, portanto, quando internalizado pelos diversos países, sua consequência é a uniformização das distintas dimensões sociais, políticas, jurídicas entre outras, sobre as quais se impõe. A liberdade humana é admitida, desde que dentro desse horizonte. Mas, as consequências desse projeto se mostraram alarmantes: a crise ambiental, o fracasso do projeto de crescimento econômico, a persistência da fome planetária, desaparecimento de tradições e culturas são algumas delas. 
Diante desse cenário, a proposta é refletir criticamente a respeito da ideia de desenvolvimento e das agendas impostas por esse "projeto global". A abordagem ou raciocínio segue a proposta metodológica de Enrique Dussel, tomando o conceito de desenvolvimento enquanto mediação reflexivo-crítica e o procedimento ou investigação segue os passos propostos na metodologia crítico-histórica de Wolkmer. Por isso, num primeiro momento, distintas concepções a respeito do desenvolvimento serão analisadas, como mediações (seguindo a proposta metodológica da ética da libertação), como também serão analisadas algumas implicações desse debate, tais como o ranqueamento dos países e as consequências das agendas desenvolvimentistas. Por fim, algumas interpelações produzidas desde uma exterioridade crítica serão inseridas, como a defesa da possibilidade/necessidade de um diálogo intercultural entre distintas tradições e da abertura ontológica a novos paradigmas.

Os debates serão situados no recorte do espaço e tempo da modernidade ocidental, cujos elementos constitutivos da realidade específica, segundo a proposição de Wolkmer, permitem compreender o fenômeno jurídico. Afinal, o discurso do desenvolvimento tem uma dimensão prescritiva que desafia a própria noção de soberania, a partir dos acordos supranacionais, para se impor sobre as agendas dos Estados-nação.

\section{PARADIGMA DE DESENVOLVIMENTO NO MODO DE PRODUÇAO CAPITALISTA}

A confluência de determinados fatores no contexto do tempo e espaço presentes culmina na formação de um fenômeno jurídico específico que se manifesta nas sociedades ocidentais, assumindo uma projeção externa aos Estados na forma de discursos de direitos humanos, desenvolvimento, entre outros. Tais discursos, por sua vez, influenciam a projeção interna do fenômeno jurídico na forma hegemonicamente manifesta do juspositivismo. A partir do aporte metodológico de Antonio Carlos Wolkmer, pode-se reunir elementos para pensar criticamente o tema e identificar certas contradições inerentes ao Direito em análise: esse que se "compartilha" nos discursos supranacionais e que é internalizado nas agendas nacionais. A proposição metodológica implica identificar o Direito como fenômeno sociocultural, inserido em contextos fáticos específicos e produzido dialeticamente a partir da interação humana. Assim identificado 
o direito, deve ser reinterpretado numa perspectiva interdisciplinar, já que o direito é reflexo de uma estrutura que abrange o modo de produção vigente, as relações estabelecidas entre as forças sociais, as estruturas de poder entre outros fatores (WOLKMER, 1999, p. 4; 2005, p. XV-xvi).

A partir dessa base epistemológica, pode-se buscar um dimensionamento do impacto que os discursos desenvolvimentistas produzem sobre o Direito. Inicialmente, importa destacar que a modernidade assume o modo de produção capitalista, um sistema cultural na perspectiva da crítica pós-colonial, ou um sistema-mundo estruturado a partir de relações econômicas em escala mundial, na abordagem do sistemamundo (GROSFOGUEL, 2010, p. 470). O capitalismo, enquanto modo de produção moderno, impõe-se como elemento decisivo na orientação da cultura jurídica ocidental e nas relações institucionais, sejam essas relações dos Estados com seus povos, sejam relações internacionais, já que a temática que aqui se propõe analisar projeta-se interna e externamente: os diferentes discursos de desenvolvimento que foram se sucedendo nas últimas décadas cumpriram - dentre outras funções - a de vincular a agenda e influenciar os sistemas de direitos dos Estados contemporâneos, especialmente os periféricos e economicamente dependentes. Um exemplo é a abertura progressiva dos Estados às relações baseadas na liberdade econômica, no poder de consumo, na busca (possível?) por aumento de renda entre outros fatores que evidenciam que

A moderna cultura liberal-burguesa e a expansão material do capitalismo produziram uma forma específica de racionalização do mundo. Essa racionalização, enquanto princípio organizativo, define-se como racionalidade instrumental positiva que não liberta, mas reprime, aliena e coisifica o homem (WOLKMER, 2012, p. 26).

Por meio do discurso do desenvolvimento difunde-se a ideia de que há países em estágios mais avançados e que, portanto, devem servir de referencial para países menos avançados. As práticas e teorizações formuladas pelos países desenvolvidos se difundem como "paradigmas", que, na definição de Ludwig (2006, p. 26), são modelos de racionalidade, padrões teóricos que em momentos específicos da história se hegemonizam, são aceitos pela comunidade que os adota como fundamento do saber a partir dos quais se compreende a realidade e se buscam as soluções. A partir do paradigma desenvolvimentista se consolida um modelo "civilizatório", atravessado pela dimensão econômica (liberal-individualista) mas também 
por outras dimensões que lhe dão coesão, como se buscará demonstrar.

A ideia de "desenvolvimento" ingressa nos debates econômicos por volta de 1950, após quase duzentos anos depois da publicação de A Riqueza das Nações de Adam Smith e da Revolução Industrial, que circunscreveram esse debate no âmbito de questões como classes sociais, renda, salário, concorrência e outros próprios das ciências econômicas. Mas, ainda que o conceito de desenvolvimento tenha se originado num contexto essencialmente econômico, rapidamente ultrapassou essas fronteiras para compor categorias compreensivas da sociologia, história, entre outras. E quando a ideia de desenvolvimento passou a abranger questões socioeconômicas, surgiu o desafio de como mensurá-lo. Nesse processo, o Produto Interno Bruto (PIB), que é um indicador de desenvolvimento que começa a ser adotado em 1947, sendo até hoje um dos principais indicadores de desenvolvimento, enfrentou duras críticas por ser um indicador meramente quantitativo, ineficaz ante a necessidade de incluir variáveis como saúde, educação e outras em seu campo de composição. Nesse contexto de críticas, especificamente nos Estados Unidos e nos anos 1960, se intensificou um novo debate, reivindicando formas de mensuração do bem-estar da população. Na década seguinte, o Reino do Butão, apoiado por iniciativa do Programa para Desenvolvimento das Nações Unidas (PNUD), propõe a "Felicidade Interna Bruta" enquanto indicador de desenvolvimento humano (SIEDENBERG, 2003, p. 4647; SALES, et al., 2013, p. 60). Isso ilustra os extremos entre os quais o debate desenvolvimentista tem orbitado: desde uma dimensão estritamente econômica até uma dimensão metafísica e de aferição talvez impossível, o campo da felicidade. Em meio a esses dois extremos, outras propostas se construíram, das quais algumas acabaram alcançando um grau maior de consolidação e, por isso, vêm exercendo forte influência sobre as agendas nacionais, seja sobre as políticas públicas, seja sobre os sistemas de direito adotados pelos países.

Esse é o caso do Índice de Desenvolvimento Humano (IDH), idealizado e apresentado pelo economista paquistanês Mahbub ul Haq e pelo economista e filósofo Amartya Sen, sendo, até hoje, mundialmente adotado pela Organização das Nações Unidas (ONU), (BARBOSA, 2017, p. 297). Após décadas de debates e polêmicas a respeito da necessidade de novos indicadores, em 1990 o PNUD apresentou esse índice, que havia sido aplicado na ambiciosa tentativa de comparação do desenvolvimento regional de cento e trinta países com mais de um milhão de habitantes. A 
sistematização do relatório revelou aspectos considerados determinantes sobre a qualidade de vida e situados para além do campo estritamente econômico (SIEDENBERG, 2003, p. 48; 66).

De fato, o IDH significou um avanço fundamental em relação aos modelos economicistas, como fica muito claro no caso do PIB. É que, assumindo o paradigma da modernização, o PIB instituía como meta a sociedade urbana e industrializada, mas não logrou fomentar o desenvolvimento econômico e social. Então, críticas sustentadas sob diversas perspectivas evidenciaram suas limitações. Dentre tais críticas, constava a discrepância entre os dados apontados ou mesmo a limitação enquanto instrumento de análise do desenvolvimento de países com alto grau de subsistência, os quais somente poderiam oferecer uma "estimativa", já que o PIB é indicador que não considera fatores extra-mercado, e, por isso, não permite avaliar as economias de subsistência, rural ou informal, frequentemente adotadas pelos "grupos marginalizados", ou ainda outra crítica aqui considerada essencial: o PIB ignora os custos ecológicos! (SIEDENBERG, 2003, p. 49-52). Em que pesem as inúmeras e contundentes críticas opostas ao PIB, esse ainda é um indicador estratégico das agências de desenvolvimento. Atualmente, o desenvolvimento é considerado sob a perspectiva econômica, em que constam indicadores como o PIB, o Produto Nacional Bruto (PNB) e o Produto Nacional Líquido (PNL) ${ }^{1}$ mas, também, é considerado sob perspectivas sociais, que se apoiam em indicadores como o Índice de Desenvolvimento Humano (IDH), o Índice de Liberdade Humana (ILH), o Índice de Liberdade Política (ILP) ou o Índice de Pobreza Humana (IPH) (SALES, et al., 2013, p. 61).

O Índice de Liberdade Humana (ILH), por exemplo, foi criado em 1991 pelo PNUD/ ONU para que, de acordo com a Declaração Universal dos Direitos Humanos e outras convenções internacionais, classificasse os países em relação ao nível de liberdade de sua população. Em 1992, foi criado pelo mesmo programa o Índice de Liberdade Política (ILP), com o intuito de medir os direitos políticos e as liberdades civis

\footnotetext{
1 David (1985, 25-26), define esses conceitos econômicos num período (anos 1980) em que o PNB predominava sobre os demais. Explica o autor que o PNB per capita pode ser calculado em qualquer país, por meio de "um conjunto básico específico de regras de mensuração que foram imaginadas nos países industriais do Ocidente para medir seu nível agregado de renda ou produção". Originalmente, tais regras não visavam mensurar desenvolvimento, mas tão somente renda e produção, o que impôs intenso debate e controvérsia ao indicador, com destaque à ausência de mensuração da distribuição de renda. Então o PNB, junto ao PIB, são dois indicadores fundamentais para as análises econômicas do desenvolvimento. Krugman (2005, p. 222) explica que o PNB é o resultado do PIB acrescido das rendas - rendimentos líquidos - vindas do exterior e que, apesar de serem indicadores compostos de modos distintos, na prática sua movimentação difere pouco.
} 
por meio do agrupamento das categorias segurança, império das leis, liberdade de expressão, participação política e igualdade de oportunidades. Logo após, em 1995 , o PNUD lançou o Índice de Desenvolvimento Ajustado ao Sexo (IDS) e a Medida da Participação Ajustada ao Sexo (MPS), ambos com vistas a medir, por meio de indicadores, as diferenças existentes entre homens e mulheres, servindo como suporte para políticas públicas futuras. Já em 2007, é lançado pelo PNUD o Índice de Pobreza Humana, que tem como foco as condições de pobreza e o desenvolvimento dos indivíduos mais pobres da sociedade (SALES, et al., 2013, p. 64).

Apesar do reconhecimento das diversas formas de opressão que se operam nas relações sociais contemporâneas - racismo, patriarcalismo, corrupção, marginalização de comunidades originárias, criminalização de movimentos sociais, populares e a lista continua sendo, por tragédia, muito mais extensa - e, apesar da evidência de que o desenvolvimento econômico não é instrumento hábil para superar essas formas de opressão, segundo Barbosa (2017, p. 296), o PIB segue sendo considerado, no âmbito das ciências econômicas, sinônimo de padrão de vida. Note-se que, mesmo no âmbito econômico, como explica o autor, é um indicador limitado: não abrange o trabalho voluntário, que beneficia a qualidade de vida, não abrange as atividades ilegais que repercutem na economia, o trabalho do "lar" entre outros. No geral, os indicadores assumem "modelos", ou referenciais de análise e, a partir desses referenciais, buscam mensurar distintas realidades. É o exemplo do ILP pautado nos institutos e categorias da democracia ocidental, ou mesmo a ideia de pobreza, vinculada à ausência de renda, em ambos os casos, índices definidos a partir da cultura ocidental moderna e aplicados nas culturas periféricas, muitas delas de tradição préexistente à modernidade.

Veja-se o caso do IDH. Dado o reconhecimento dos déficits de indicadores econômicos, o IDH surge como uma das principais formas para viabilizar uma avaliação global do desenvolvimento social; por isso, é expressamente reconhecido pelos organismos internacionais como uma ferramenta alternativa ao PIB per capita, um "contraponto" a esse indicador. Esse índice, o IDH, é reconhecido como um avanço em relação aos indicadores de cunho mais restritamente econômicos, mas, igualmente, é reconhecida sua limitação na representação da "felicidade", ou de identificação de bons "lugares para se viver", pois esse indicador não contempla informações como o nível democrático da sociedade, a sustentabilidade e outros fatores (PNUD, s.d.b). A ONU passa a relacionar 
- e nisso se nota a forte influência de Amartya Sen - o conceito de "desenvolvimento humano" com a possibilidade de ampliação das escolhas das pessoas, de modo a lhes permitir desenvolver capacidades e acessar oportunidades, para "serem aquilo que desejam ser" (PNUD, s.d.a). Ainda se reconhece a renda como um fator importante, mas agora se rejeita a ideia de identificar o desenvolvimento com fatores meramente econômicos. Então, a renda é tida como "um dos meios do desenvolvimento" e não como fim. A respeito da construção do IDH, informa o PNUD que:

Desde 2010, quando o Relatório de Desenvolvimento Humano completou 20 anos, novas metodologias foram incorporadas para o cálculo do IDH. Atualmente, os três pilares que constituem o IDH (saúde, educação e renda) são mensurados da seguinte forma:

* Uma vida longa e saudável (saúde) é medida pela expectativa de vida; * O acesso ao conhecimento (educação) é medido por: i) média de anos de educação de adultos, que é o número médio de anos de educação recebidos durante a vida por pessoas a partir de 25 anos; e ii) a expectativa de anos de escolaridade para crianças na idade de iniciar a vida escolar, que é o número total de anos de escolaridade que uma criança na idade de iniciar a vida escolar pode esperar receber se os padrões prevalecentes de taxas de matrículas específicas por idade permanecerem os mesmos durante a vida da criança;

* E o padrão de vida (renda) é medido pela Renda Nacional Bruta (RNB) per capita expressa em poder de paridade de compra (PPP) constante, em dólar, tendo 2005 como ano de referência. (PNUD, s.d.b).

Com base nesses indicadores, os resultados do relatório do ano de 2016 apontaram os dez índices mais altos respectivamente na Noruega, Austrália, Suíça, Alemanha, Dinamarca, Singapura, Países Baixos, Irlanda, Islândia, Canadá e Estados Unidos. O Reino Unido ficou situado na décima sexta posição, seguido pelo Japão. A França na vigésima terceira. Entre as últimas posições, a República Centro-Africana (188 a), ascendendo timidamente para a Nigéria, Chade, Burkina Faso, Burundi, Guiné... Enfim, os índices despencam e se mantêm baixos nessa determinada localização geográfica, o continente africano. No caso dos países latino-americanos e caribenhos verificam-se expressivas variações (mais de cem posições!), dentre as quais: Argentina $\left(45^{\circ}\right)$, o Uruguai $\left(54^{\circ}\right)$, Cuba $\left(68^{\circ}\right)$, México $\left(77^{\circ}\right)$, Brasil $\left(79^{\circ}\right)$, Equador $\left(89^{\circ}\right)$, Colômbia $\left(95^{\circ}\right)$, Paraguai $\left(110^{\circ}\right)$, Bolívia $\left(118^{\circ}\right)$ e Haiti $\left(163^{\circ}\right)$ (PNUD, 2017, p. 198-201). 
Para classificar os países em mais ou menos desenvolvidos, é construída uma escala na qual ao mais alto índice corresponderá o indicador "um" e ao menor índice, o indicador "zero". Entre os dois indicadores, situam-se as posições relativas de cada país. Essa classificação apresenta diferenças ao ser cotejada com outros rankings definidos em função da renda per capita e gera algumas perplexidades na percepção de determinados estudiosos, como a "boa posição relativa dos países socialistas, onde os direitos humanos sabidamente nem sempre foram respeitados"2(SIEDENBERG, 2003, p. 67). Mas a verdade é que, por mais que variem seus componentes, os resultados na classificação global permanecem idênticos ou muito semelhantes. Nesse sentido, notase que, assim como no PIB per capita, o ranking do IDH indica entre as primeiras posições basicamente os mesmos países ${ }^{3}$; um indicativo da influência do fator econômico no ranqueamento dos países tidos como mais desenvolvidos. Inclusive, o terceiro pilar do IDH, o poder de compra per capita, pode ser considerado mais como mero indicador de consumo do que de desenvolvimento humano, já que para inúmeras culturas as transações comerciais não têm o mesmo sentido que para as sociedades capitalistas ocidentais. Outro indicador, de "acesso ao conhecimento", ao vincular-se à educação formal, adotando como critério quantitativo para aferição os anos de permanência na escola, nega às culturas periféricas o reconhecimento de formas distintas de conhecimento, presumindo que o conhecimento válido e indicativo de desenvolvimento humano é somente aquele construído nas instituições oficiais. Mas, além dessas oposições externas, há outras críticas às limitações do IDH, algumas construídas internamente.

Nesse sentido, a própria ONU reconheceu limites nos instrumentos globalmente aplicados para aferição e ranqueamento das condições gerais dos países, de modo que, em 19 de julho de 2011, a Assembleia Geral da ONU adotou a Resolução 65/309, Felicidade: para um enfoque holístico

2 A respeito dessa perplexidade, sublinha-se a ideia que vem sendo defendida aqui: a de que os indicadores, sejam econômicos, sejam sociais, são instrumentos concebidos por uma racionalidade especifica, no caso, a racionalidade moderna ocidental, ambientada num sistema econômico determinado: o capitalismo. Pensando assim, de fato, deve ser desconfortável para países capitalistas centrais, verificarem bons resultados dos Estados socialistas, especialmente, quando esses Estados têm bom desempenho se submetendo a critérios incompatíveis com conformações políticas e econômicas a partir das quais os indicadores de desenvolvimento são traçados.

3 Segundo dados extraídos do Fundo Monetário Internacional em abril de 2017 e publicados pelo Instituto de Pesquisas em Relações Internacionais (IPRI) os maiores PIB per capita estimados ou confirmados em 2016 são, em ordem decrescente, os de: Luxemburgo, Suíça, Noruega, Macau, Irlanda, Catar, Islândia, Estados Unidos, Dinamarca, Singapura, Austrália, Suécia (IPRI, 2016). 
do desenvolvimento, na qual reconhece a "que a busca da felicidade é um objetivo humano fundamental" (tradução livre ${ }^{4}$ ), um objetivo universal. Ainda dentre as considerações iniciais, apresenta crítica ao PIB, que não reflete adequadamente a felicidade e o bem-estar das pessoas, outra crítica aos padrões insustentáveis de produção e consumo, e defende a necessidade de abordagem "mais inclusiva, equitativa e equilibrada do crescimento econômico que promova o desenvolvimento sustentável, a erradicação da pobreza, a felicidade e o bem-estar de todos os povos" (tradução livre $^{5}$ ). A partir dessas considerações, a proposta da resolução é de convidar ${ }^{6}$ os Estados-membros a elaborar, ou prosseguir na elaboração de medidas que fomentem a "busca pela felicidade", incluindo-as em suas políticas públicas, assim como, a desenvolver novos indicadores e medidas que permitam o compartilhamento de informações a respeito do tema.

O ideal da felicidade coloca na pauta da ONU um novo indicador: o índice de Felicidade Interna Bruta (FIB), que, contando com o apoio do PNUD, foi desenvolvido no Butão, na década de 1970; um índice que "procura medir o progresso da sociedade a partir dos domínios: padrão de vida, educação, saúde, governança, cultura, vitalidade comunitária, resiliência ecológica, uso equilibrado do tempo e bem-estar psicológico" (MOREL, et al., 2015, p. 84). Mediante os critérios empregados para "medir a felicidade", o ranking de 2014-2016 indica entre as primeiras posições, em ordem decrescente: Noruega, Dinamarca, Islândia, Suíça, Finlândia, Países Baixos, Canadá, Nova Zelândia, Austrália, Suécia. Mas, o Brasil avança significativamente nesse índice, em relação aos anteriores: ocupa a vigésima segunda posição. E dentre outros países latinoamericanos, constam: Argentina $\left(24^{\circ}\right)$, Colômbia (36 $)$, Equador $\left(44^{\mathrm{a}}\right)$ e Bolívia $\left(58^{\mathrm{a}}\right)$. Na última posição, novamente a República Centro-Africana $\left(155^{\mathrm{a}}\right)$ (HELLIWELL; LAYARD; SACHS, 2017, p. 20-22). Note-se que, apesar das variações metodológicas e de conteúdo, na composição das

4 "Conscious that the pursuit of happiness is a fundamental human goal"

5 " [...] more inclusive, equitable and balanced approach to economic growth that promotes sustainable development, poverty eradication, happiness and well-being of all peoples"

$6 \mathrm{O}$ tema da felicidade e o convite das Nações Unidas chamaram atenção do constituinte derivado, de modo que chegou a tramitar em 2010 no Senado Federal uma Proposta de Emenda à Constituição, visando incluir nela o direito à felicidade. Foi a PEC da Felicidade! A tramitação está encerrada, pois a proposta foi arquivada. A proposta, apresentada pelo Senador Cristovam Buarque, vinculava os direitos sociais e a "busca pela felicidade", uma empreitada que, individual ou coletivamente, precisaria contar com a atuação do Estado, cujo dever consiste em cumprir suas obrigações corretamente, prestando serviços sociais, entre outros. Antes de ser arquivada, houve uma emenda na redação da proposição, para evitar que a emenda transformasse os direitos sociais em acessórios à "busca pela felicidade", que ficou com a seguinte formulação: "Altera o art. $6^{\circ}$ da Constituição Federal para direcionar os direitos sociais à realização da felicidade individual e coletiva" (AGÊNCIA SENADO, 2011. Grifo original). 
classificações, basicamente, os mesmos países se mantêm nas melhores posições, assim como, basicamente, os mesmos países permanecem nas piores.

É notória a dificuldade em construir um instrumento global de medição do desenvolvimento. As diferentes propostas construídas não são isentas de contradição, mesmo a partir de perspectivas internas, ou "coloniais". Um exemplo se extrai da análise de Amartya Sen, cujo pensamento é marcado pelo liberalismo e individualismo. Consignando uma crítica ao conceito de "felicidade" e sua admissão enquanto indicador social, Amartya Sen (2011, p. 317-318) sustenta que a economia do bemestar durante muito tempo adotou como critério único a felicidade para avaliar o bem-estar humano. Entretanto, não considera possível relacionar o crescimento econômico ao aumento de felicidade, mesmo porque, muitas sociedades enriqueceram e não se tornaram mais felizes. Por outro lado, a exposição constante a situações de privação leva a pessoa a se adaptar a tais privações e suportá-las. Isso evidencia que uma mensuração simplesmente através da felicidade ou satisfação dos desejos poderia distorcer aspectos importantes da realidade. Resgatando o componente econômico, conclui que "[d] esconsiderar a intensidade de sua desvantagem apenas por causa de sua capacidade de experimentar um pouco de alegria em suas vidas não é um bom caminho para alcançar uma compreensão adequada das exigências da justiça social." (SEN, 2011, p.318).

Com relação à FIB, o relatório mundial de 2017 detalha os oito componentes do ranking (HELLIWELL; LAYARD; SACHS, 2017, p. 17). Alguns desses componentes parecem avançar para além do olhar estritamente econômico, como o "apoio social", que visa indicar o nível de solidariedade e suporte interpessoal. Por outro lado, o primeiro componente apresentado é o PIB per capita, do qual se extrai mensuração do poder de compra da sociedade. Inclusive o componente "generosidade" é aferido pela resposta ao questionamento: "você doou dinheiro para a caridade no mês passado?" (tradução livre). ${ }^{7}$ Evidente que o quesito assim formulado desconsidera outras formas de cooperação para além da econômicofinanceira, estabelecidas entre a comunidade, tais como mutirões ou trabalhos comunais e voluntários. $\mathrm{O}$ mesmo se dá com o componente "apoio social", visto que se limita à solidariedade entre amigos e familiares, ou seja: somente coletividades reconhecidas na cultura moderna ocidental

7 "Have you donated money to a charity in the past month?" 
e não contempla outros sujeitos coletivos, como os ayllus $^{8}$, fundamentais às sociedades latino-americanas pré-coloniais. Além disso, a estrutura dos quesitos dirigidos aos entrevistados limita as respostas a opções binárias, como sim ou não, o que pode provocar uma distorção da realidade, que é mais complexa do que a racionalidade cartesiana permite dimensionar.

\section{DISCURSOS DE DESENVOLVIMENTO: IMPACTO NO DIREITO AMBIENTAL E RISCO À BIODIVERSIDADE}

Dos elementos anteriormente expostos, nota-se que o desenvolvimento, enquanto categoria interpretativa e normativa supranacional, pretensamente global, manteve em suas variadas manifestações a concepção monocultural resultante do sistema capitalista e do mito civilizatório, que coloniza as formas de vida consideradas não civilizadas. É uma forma contemporânea de dominação, manifesta também em outras épocas (ainda que com conteúdos distintos), pela "dicotomia civilização/barbárie como signo do poder e dependência, de centro e periferia. Povos destinados a ser dominados por serem bárbaros, isto é, por não serem cópia exata de seu dominador" (ZEA, 2005, p. 52). Nesse sentido, destacam-se duas consequências que incluem entre suas causas a difusão desse paradigma.

A primeira delas diz respeito a um paradoxo mais ou menos aparente nos diferentes discursos do desenvolvimento, mas inegável diante da crise ambiental e gravíssima ameaça à biodiversidade global, e que pode ser sintetizada na seguinte questão: Como os países periféricos podem se desenvolver preservando o meio ambiente?

O paradoxo está na impossibilidade de que os países periféricos conciliem desenvolvimento e sustentabilidade ambiental. E seja pelo PIB, IDH ou FIB, a renda - poder de consumo- é um dos principais componentes considerados. O interessante é notar que os Estados "mais desenvolvidos", alcançaram suas posições a partir da exploração de recursos naturais, inclusive externos: outrora pela dominação colonial e contemporaneamente pelas relações produtivas instituídas no contexto do mercado mundial. Agora essas sociedades apelam aos Estados periféricos

8 Os ayllus eram pequenas comunidades que abrangiam um conjunto (que podia chegar a centenas) de famílias e uniam-se por laços de parentesco ou aliança. Têm sua origem nos incas - especialmente quéchuas e aymarás - os quais eram a "célula" da sociedade, desconhecendo a divisão de classes ou a propriedade privada. Também adotavam o trabalho cooperativo e ajuda mútua (CÁRCERES, 1992, p. 17; 27; JESUS OSCAR, 2000, p. 69). 
e de "economia subdesenvolvida" que respeitem suas florestas e lençóis freáticos e que alcancem os mesmos patamares de desenvolvimento, ainda que privados dos meios que têm servido aos países centrais.

Essa dinâmica enseja contradições no âmbito das ordens jurídicas nacionais, especialmente com relação ao direito ambiental. O Brasil é um caso emblemático: apesar da ampla proteção constitucional, a regulamentação ordinária prevê uma série de mecanismos de conciliação com o desenvolvimento capitalista, que dificultam ou mesmo impedem a efetivação da proteção do ecossistema. Aliás, a ausência ou ineficácia de normas de preservação do meio ambiente são comuns nos ordenamentos jurídicos dos Estados ocidentais. Não surpreendem, portanto, os patamares alarmantes dos problemas ecológicos. Segundo Dardot e Laval (2017, p. 13), relatórios desenvolvidos por programas do PNUD têm apontado "o aquecimento global como o problema mais grave e urgente que a humanidade já enfrentou", de modo que os padrões de relação entre a sociedade humana e o restante da natureza poderão conduzir a intensas guerras e disputas pelos recursos naturais.

O sistema capitalista mantém sua hegemonia nos espaços deliberativos dos organismos e programas supranacionais, apesar da evidência de que esse modelo - baseado no desenvolvimento industrial e ampliação das relações de consumo - está conduzindo a vida na terra ao colapso. Mais que isso: seu horizonte civilizatório rejeita as formas de produção e reprodução da vida integradas aos demais elementos da natureza e não orientadas pela produção e consumo de excedentes, o que conduz ao segundo aspecto decorrente do discurso desenvolvimentista: o seu êxito implica no progressivo desaparecimento não somente da biodiversidade, como já o tem feito em relação também à diversidade humana.

Uma crítica mais precisa é exposta nos dizeres de Celso Furtado (1980, p. 46-47):

A reflexão sobre o desenvolvimento econômico tem-se concentrado no estudo do processo acumulativo ao nível das forças produtivas. Ora, por trás dos indicadores quantitativos que preocupam o economista, desdobra-se o vasto processo histórico de difusão da civilização industrial: a adoção por todos os povos da terra do que se convencionou chamar de padrões de modernidade, ou seja, a forma de viver engendrada pela industrialização dos países que a lideram. Daí que o papel da criatividade no desenvolvimento haja perdido nitidez, bem como toda relação entre a acumulação e os valores que presidem a vida social. Essa simplificação oculta 
a existência de modos de desenvolvimento hegemônicos que monopolizam a inventividade ao nível dos fins em benefício de certos países (grifos no original).

Mas a ideia de desenvolvimento econômico não enfrenta somente críticas externas. A partir de sua própria plataforma compreensiva, tem certos limites evidenciados. Foi o caso das críticas sustentadas por Amartya Sen, que contribuíram ou confluíram diretamente para adoção de novas metodologias e componentes nos indicadores globais, sem, contudo, superar o monopólio da razão imposto desde os países centrais. Amartya Sen (2000, p. 18-26) em relação ao PNB como indicador de desenvolvimento, o identifica como um meio de expandir as liberdades, mas não mais que parte de um processo em que constam outras determinantes. Avalia, então, que há fontes que prejudicam o alcance da liberdade, as fontes de privação da liberdade: pobreza e tirania, na carência de oportunidades econômicas, na negligência nos serviços públicos e na intolerância ou interferência excessiva do Estado repressivo. Então as fontes identificadas pelo autor têm nítido caráter econômico e institucional. Uma percepção eurocêntrica da liberdade que repercutiu profundamente na pauta dos organismos internacionais, de modo que o enunciado de liberdade formulado pela ONU se sustenta sobre bases bem específicas.

Para a ONU, liberdade e desenvolvimento humano implicam na possibilidade de cada ser humano "ser aquilo que deseja ser". Apesar disso, analisa e classifica os mais distintos países aplicando os mesmos critérios. O componente renda ou poder de consumo, por exemplo, é uma constante nos diversos índices, inclusive o IDH. Esse mesmo índice abrange o pilar da educação, que considera o tempo de permanência nas escolas para sua definição quantitativa. Mas somente escolas componentes do sistema estatal de educação. Segundo tais critérios, ficam prejudicados no ranking global Estados plurinacionais, como os latino-americanos, cujos sistemas tradicionais de educação não cumprem os critérios do IDH, já que não reconhecem a educação oficial do Estado como única forma de conhecimento válida. O paradigma de desenvolvimento humano decorrente do IDH refina a perspectiva econômica, mas não a supera, assim como não significa uma alternativa ao modelo ocidental hegemônico, o qual avança na uniformização da política, da Economia e do Direito, apesar dos efeitos perversos que produz.

Então, parece que uma melhor formulação para a ideia de liberdade da "comunidade internacional" seria: "[1]ivre para ser aquilo 
que deseja ser, desde que cumprindo o que a racionalidade ocidental moderna determina". Eis aí o mito da modernidade que assume um horizonte civilizatório baseado na economia capitalista, no indivíduo abstrato, no monopólio da ciência entre outros fatores que culminam no que Dussel denomina "en-cobrimento" do outro. Na negação da alteridade pela totalização de determinado sistema. Como os pressupostos do sistema capitalista moderno são naturalizados como o único caminho para desenvolvimento da liberdade - mais claramente: não reconhecem liberdade sem desenvolvimento econômico capitalista - é necessário expor as contradições e efeitos desse mesmo sistema, cujos valores não são naturais, tampouco universais.

A razão ético-crítica descobre no fenômeno da totalização do sistema o "mal originário". Trata-se de um sistema indiferente à factibilidade da reprodução da vida e participação das vítimas. O paradigma, seja qual for sua designação (Sistema de Luhmann, Identidade de Hegel, Mundo de Heidegger, Mercado de Hayek) se fecha sobre si e se torna incapaz de re-conhecer a alteridade e autonomia da vítima (o en-cobrimento do Outro através do mito da Modernidade). Esse sistema fechado, a totalidade, encaminha-se para o suicídio coletivo, como se vê nos problemas ecológicos, nas dívidas inventadas e impagáveis da América Latina entre outros. E corporalidade da dor das vítimas - dimensão material inegável, já que a dor é momento do sistema neurocerebral - é a origem material de toda crítica ética possível: permite o juízo de fato crítico: "não permite a reprodução da vida" e o juízo normativo crítico: "é mau porque não permite a reprodução da vida" (DUSSEL, 2012, p. 305-306).

$O$ processo de transformação desse sistema não exige necessariamente uma revolução, uma vez que as transformações podem ocorrer cotidianamente, conforme a proposta da Ética da Libertação, que "é uma ética do cotidiano". Esse processo que tem distintos níveis, segundo Dussel, começa com a negação pelas vítimas das formas de alienação que lhes atingem, pela afirmação da vida negada, pela descoberta de uma consciência ético-crítica a partir da qual se formularão juízos críticos frente às instituições e sistemas injustos e perversos. Segundo momento é aquele em que as vítimas aprofundam sua consciência por meio de interpelações recíprocas e expressam sua solidariedade para com aquelas vítimas que ainda não assumiram sua própria consciência. Agora o diálogo crítico ultrapassa a comunidade das vítimas e se difunde por outros campos, onde surge a colaboração militante que amplia a comunidade prático- 
crítica diante do sistema. Então, a tomada de consciência e explicação científica das causas de negação das vítimas constrói, de modo antecipado e afirmativo, alternativas possíveis para exercício da razão utópica (aquela entre a anarquia e o conservadorismo). No cume do processo, ocorre desconstrutivamente a negação real das negações sistêmicas das vítimas com ações transformadoras e eticamente factíveis e ocorre a construção de novos momentos (ações, normas, instituições) a partir de critérios factíveis: esse é o momento estrito da práxis de libertação (DUSSEL, 2012, p. 310312).

Dussel, que parte das teorias e sistemas enquanto mediações reflexivas, não parte do pressuposto de que, por seus efeitos perversos, precisam ser enfática e totalmente negadas, mas antes, de uma evolução dialética que reconheça os avanços e limites de um dado cenário, para transformá-lo criticamente. A mediação aqui assumida como objeto de reflexão, o desenvolvimento, precisa ser enfrentada criticamente e desde a perspectiva das vítimas que não constroem os consensos e paradigmas cujos efeitos enfrentam. Nessa perspectiva, a crítica de Herrera Flores (2002, p. 21) aos direitos humanos se aplica também ao horizonte do desenvolvimento: ambos são abstração científica e política que busca impor um horizonte universal para a humanidade, baseado num universalismo que se impõe não somente como ponto de chegada, mas já constitui o ponto de partida.

Omomentonecessárioenquantoponto departida-oparticularismo da tradição - não é razão suficiente para excluir a possibilidade de diálogo intercultural e crítico. Para a ética da libertação, existe um princípio material universal que é a reprodução e desenvolvimento "da vida de cada sujeito humano em comunidade", a partir do qual, com condições formais adequadas, é possível um diálogo entre tradições, corrigindo-as a partir de interpelações externas (exterioridade crítica) e internas (a partir de um princípio material: a vida humana), (DUSSEL, 2012, p. 117).

O único universalismo válido consiste, pois, no respeito e na criação de condições sociais, econômicas e culturais que permitam e potenciem a luta pela dignidade: em outras palavras, consiste na generalização do valor da liberdade, entendida esta como a "propriedade" dos que nunca "existiram"na construção das hegemonias (HERRERA FLORES, 2002, p. 27). 
Ambos os autores convergem ao considerar que o diálogo intercultural oferece condições para escapar dos universalismos e dos processos totalizantes. As perspectivas desenvolvimentistas, mesmo as mais progressistas, sao construídas a partir das críticas internas e não são submetidas efetivamente à exterioridade crítica. Outros paradigmas são possíveis, como a subjetividade coletiva e não somente a individual, como a cosmovisão e reconhecimento da plena integração humana à natureza enquanto alternativa à dicotomia civilização $x$ natureza, ou ainda o trabalho comunal e de subsistência, para além da produção capitalista de excedentes e de consumo (o consumo que é fatalmente ilimitado no modelo capitalista), cujos valores se irradiam sobre as ordens jurídicas e processos políticos de países por todos os continentes, por meio das agendas de desenvolvimento.

\section{BENS COMUNS E DESCOLONIZAÇÃO DO DESENVOLVIMENTO}

Novas perspectivas teórico-científicas têm se manifestado revelando a complexidade das questões referentes ao meio-ambiente e os limites normativos da tutela estatal - legal ou jurisprudencial - na matéria. Uma plataforma que reúne diversos conceitos, mais ou menos conexos e eventualmente empregados como sinônimos, é a ideia de "comum" ou "comuns", ou ainda "bens comuns". No âmbito desse debate, espaços internacionais comuns são reconhecidos e retirados do domínio político de qualquer Estado-nação. Nesses espaços situam-se os "bens comuns globais" (Alto mar, atmosfera, Antártida e Espaço Exterior). Sob outra perspectiva - a dos críticos do sistema capitalista - o termo "comum" tem sido proposto para designar práticas, lutas, instituições e pesquisas para além do capitalismo (RUSCHEL, 2018, p. 109-111).

Nessa perspectiva, o "comum" é tema que surgiu nos anos 1990, nas lutas sociais e políticas, como princípio de combate e resistência ao capitalismo e à tendência dominante de apropriação privada de todas as esferas da sociedade, cultura e vida. Não se trata de ressurgimento de ideia comunista, pois dá as costas ao comunismo de Estado, mas do surgimento de uma nova forma de contestação do capitalismo. O termo "comum" referencia-se no termo "commons" em oposição ao segundo avanço de cercamentos que abrangeu campos e prados suprimindo as apropriações e utilizações coletivas de terras (comunais) que se instituíam 
num processo multissecular. Isso inclui o esforço em desenvolver formas de administração "em comum" de recursos partilhados (tanto naturais quanto de conhecimento), pelo protagonismo de coletividades e para além do mercado e do Estado. Dentre os teóricos que têm se dedicado a essa tarefa, o pioneirismo é atribuído a Michael Hardt e Antonio Negri, que, a partir das experiências concretas "dos comuns", abstraíram a concepção de "comum" que passou a designar lutas, práticas, instituições e pesquisas voltadas a um futuro não capitalista (DARDOT; LAVAL, 2017, p. 16-18).

Em outubro de 2005 foi realizado na Universidade Federal do Rio de Janeiro (UFRJ) o II Seminário Internacional sobre Capitalismo Cognitivo, ocasião em que Antonio Negri proferiu conferência (TOJAL, 2008), posteriormente publicada na Colômbia, em uma compilação de textos do autor. No capítulo referente a essa conferência, intitulado "A Constituição do Comum", Negri (2012, p. 186) caracteriza o comum como

[...] fundamentalmente articulado, no sentido mais pleno da palavra, com o movimento e a comunicação das singularidades. Não existe um comum que possa ser atribuído simplesmente a elementos orgânicos ou identitários. O comum é sempre construído por um reconhecimento do outro, por uma relação com o outro que desenvolve nessa realidade. Às vezes denominamos essa realidade multidão, porque quando se fala em multidão, de fato, se fala de uma série de elementos que objetivamente estão nela e que constituem o comum (tradução livre ${ }^{9}$ ).

Com tal caracterização, o filósofo italiano aproxima comum, alteridade e interculturalidade, mais precisamente, diálogo intercultural, conceitos fundamentais nos processos de resistência ao capitalismo e eurocentrismo. Numa releitura das ideias de Negri e apontando diversos elementos que evidenciam essa necessidade de resistência, Dardot e Laval avaliam que ainda não há suficientes forças contrárias ao capitalismo. $\mathrm{O}$ operariado está enfraquecido, cresce o ódio xenofóbico e o nacionalismo, faliu o Estado comunista entre outros fatores que suscitam o questionamento de ainda haverem modelos alternativos a esse sistema econômico, que, mesmo demonstrando continuamente a incapacidade de resolver as crises que produz, segue desenvolvendo sua lógica e estendendo seu domínio sobre

$9[\ldots]$ fundamentalmente articulado, en el sentido más pleno de la palabra, con el movimiento y la comunicación de las singularidades. No existe un común que pueda ser referido simplemente a elementos orgánicos o a elementos identitarios. Lo común es siempre construido por un reconocimiento del otro, por una relación con el otro que se desarrolla en esa realidad. A veces llamamos a esa realidad multitud porque cuando se habla de multitud, de hecho, se habla de toda una serie de elementos que objetivamente están allí y que constituyen lo común. 
a sociedade. Mas a situação é cada vez mais intolerável, pois esse sistema está destruindo as condições de vida planetária e promovendo a destruição do homem pelo próprio homem. O surgimento do neoliberalismo, a partir dos anos 1980, estendeu a lógica da concorrência por toda a sociedade, impôs a lógica da superação e desempenho infinito, da acumulação infinita, que transforma as sociedades, suas relações e subjetividades (DARDOT; LAVAL, 2017, p. 11-14).

O conceito de desenvolvimento, ao não conseguir ultrapassar as fronteiras do sistema econômico capitalista e da racionalidade moderna liberal-individualista, impõe-se como um dos instrumentos pelos quais essa lógica que ameaça a vida planetária e rejeita formas de produção e reprodução da vida, alheias aos valores pretensamente universais. Por essa razão, o discurso do desenvolvimento precisa ser "descolonizado", para que possa também ser descolonizado o discurso político e o discurso jurídico que reproduzem, no âmbito dos países, o horizonte civilizatório definido pelo capitalismo.

Uma das bases do desenvolvimento é a ideia de "propriedade" que define inclusive a percepção humana da natureza, que, no antropocentrismo ocidental, é tida como "objeto de direito" ou "bem comum" à disposição das sociedades humanas em sua marcha pelo progresso. Segundo essa percepção, o ser humano não integra a natureza, mas separa-se dela ao civilizar-se. Por isso, a cautela necessária na identificação dos sentidos do conceito de bem comum, que tanto pode ter caráter descolonial, quanto reproduzir a lógica capitalista: assim, bens comuns, em geral, é conceito adotado para designar recursos naturais objeto de propriedade, mas também pode designar as propriedades comunais. Bem comum, por sua vez, no âmbito jurídico, impõe-se como finalidade do sistema normativo, finalidade das leis que reúnem os seres humanos, geralmente, dentro de um território específico. Aproxima-se do conceito de interesse público. O bem comum da terra ou humanidade em certas perspectivas - como a de François Houtart - é conceito baseado em alternativas ao capitalismo, enquanto modelo econômico que domina todas as áreas e dimensões da existência humana, e sua justificativa vincula-se à necessidade de rever o paradigma de vida imposto pela lógica capitalista (RUSCHEL, 2018, p. 112-114). Em todo caso, a superação da lógica proprietária do capitalismo é considerada como condição de possibilidade para a manutenção da diversidade humana, dos ecossistemas, da biodiversidade, enfim, da vida no planeta. 
É o indivíduo proprietário que vai orientar o desenvolvimento do direito ocidental desde sua origem na experiência romana do século $\mathrm{V}$ d.C., até suas expressões contemporâneas, cuja ideologia ainda é produzida pelas classes proprietárias e que seguem difundidas nas escolas de direito de maneira hegemônica. Tal contexto faz dos bens comuns uma ideia marginal, incompatível com a juridicidade ocidental, que retoma o direito romano e o requalifica para atender às necessidades do capital. Isso resulta numa juridicidade pautada na "combinação universalizante e exaustiva entre a propriedade privada e a propriedade do Estado, lidos recentemente com os olhos da retórica dos direitos individuais" (NEGRI, 2012, p. 195197). Então, os bens comuns naturais podem ser concebidos para além da dicotomia público-privado e, portanto, não abertos à apropriação, monopólio e exploração, sentido em que estarão para além do capitalismo. Por outro lado, para além dessa própria concepção - uma das que podem ser construídas no campo do comum - estão as perceptivas biocêntricas ou ecocêntricas, para as quais natureza não é recurso, não é bem, mas sim, componente da vida, assim como é o próprio ser humano.

Por isso, a cosmovisão ancestral andina, enquanto oposição à racionalidade antropocêntrica, reúne pressupostos que permitem pensar formas de resistência ao capitalismo e ao antropocentrismo. Inclusive porque as lutas protagonizadas pelos povos andinos logrou conquistas importantes, como a transformação formal ${ }^{10}$ de sistemas jurídicos e dos processos políticos nos países em que foram deflagradas. Negri (2012, p. 190-191) define a resistência na América Latina e de outros colonizados, como "experiências formidáveis de resistência nos países coloniais", resistências deflagradas pelas comunidades que, mesmo vivendo dentro da derrota, sofrendo a repressão, seguiam propondo modelos alternativos; não utopias, mas realidades oprimidas que podem construir o novo.

A oposição da percepção dos sujeitos coletivos concretos ao paradigma do indivíduo abstrato, o reconhecimento de que a natureza não é mero objeto ou bem jurídico, mas sim sujeito de direitos, assim como o reconhecimento de que o ser humano integra a natureza, o trabalho comunal para manutenção da vida enquanto uma das alternativas ao trabalho assalariado para produção de excedentes, dentre outros valores, implicam numa abertura intercultural e descolonial nos sistemas normativos. São

10 Importante sublinhar as transformações formais, no sentido estrito de novas enunciações nos textos das normas, porque as transformações concretas, ou seja, materiais, são objeto de controvérsias cada vez mais intensas, tanto no que se refere ao respeito pelos direitos da natureza, quanto ao respeito pelo direito de autodeterminação de comunidades pré-coloniais latino-americanas (FERRAZZO, 2015). 
valores inseridos em textos constitucionais na América Latina, desafiando o que o constitucionalista argentino, Alejandro Médici, define como reificação da natureza e mercantilização da vida (FERRAZZO, 2015, p. 256266). É sob essa perspectiva que se considera urgente repensar o discurso do desenvolvimento, permitindo a convergência da percepção do comum para além da lógica capitalista de reificação da natureza, contemplando processos e lutas que permitam o desenvolvimento de outras razões, outras formas de organizar a vida e outras formas de compreender o mundo.

\section{CONCLUSÃO}

A proposta de reflexão esboçada assumiu como método de abordagem ou raciocínio a proposição de Enrique Dussel em sua Ética da Libertação, que, a partir de determinadas categorias, estabelece mediações pelas quais se problematiza e se compreende a realidade. No caso, o estandarte moderno do desenvolvimento, do qual decorre uma forma prescritiva que vincula as políticas públicas, o espaço democrático e o sistema de direito de países em todos os continentes, em especial o direito ambiental, em que fica evidente um paradoxo: conciliar a preservação dos ecossistemas com as necessidades do desenvolvimento capitalista. $\mathrm{Da}$ impossibilidade de atender ambas, resultam normas precárias em sua eficácia e repletas de lacunas ou espaços permissivos de exploração ambiental, como se percebe no direito ambiental brasileiro, com os mecanismos de compensação ambiental.

A análise dos principais indicadores adotados pelas organizações internacionais, em especial a ONU, revela que, por mais distintos que pareçam ser, todos reproduzem a lógica capitalista e não reconhecem formas alternativas aos paradigmas decorrentes dessa lógica, como o acúmulo de renda e propriedade, o consumo, o individualismo abstrato.

Procurou-se, portanto, delinear algumas formas de apresentação dos paradigmas eurocêntricos a partir do impacto global que a ideia de desenvolvimento provoca. Isso porque, a agenda colocada para os diversos países a partir das distintas concepções desenvolvimentistas e seus respectivos indicadores conduz aos mesmos modelos sociais e institucionais, tanto que a classificação estabelecida a partir dos distintos indicadores conduz a resultados similares ou idênticos. Em diferentes contextos, basicamente os mesmos são os melhores ou mais desenvolvidos (os ditos 
países centrais) e os mesmos são os piores, menos ou subdesenvolvidos (os países periféricos). Os indicadores, por meio de seus rankings de países mais desenvolvidos, com maior crescimento econômico, os mais felizes expressam uma concepção mais próxima da competição que da cooperação e dão largada a uma corrida perversa, por meio da qual os países periféricos precisam alcançar um elevado nível de desenvolvimento industrial, mas sem utilizar o mesmo expediente que permitiu aos países centrais alcançar o seu próprio desenvolvimento: a exploração dos recursos naturais.

Naturalmente, não é a noção de preservação ecológica que se problematiza - essa é mais que necessária, é crucial para a manutenção da vida -, mas sim, os pressupostos industriais e capitalistas inarredáveis do desenvolvimento, dessa concepção ocidental especificamente, que, como bem apontou Celso Furtado, é expressão da "forma de viver engendrada pela industrialização dos países que a lideram". Por conta dessa concepção, predominante no âmbito da ONU, tem sido utilizada a "mesma régua" para medir coisas diferentes. Por isso, realidades periféricas vão sendo suprimidas e culturas conduzidas ao desaparecimento, assim como vai se tornando mais grave o risco de desaparecimento da vida na terra.

O paradoxo - ou armadilha - colocado pelo desenvolvimento é que em todas a formas pelas quais se manifestou no âmbito das instituições internacionais reconduziu sempre ao mesmo paradigma: da propriedade, consumo, capitalismo, ainda que se expresse na versão atenuada do “desenvolvimento sustentável”. Esse paradigma não é um horizonte ao alcance das sociedades espoliadas, muitas das quais tiveram suas terras sugadas até o completo esgotamento, restando-lhes os desertos e a miséria artificialmente construídos pela ganância. Por isso, é importante perceber que se as metas de desenvolvimento permitem em certos sentidos alguma melhora nas condições de vida das pessoas, as mesmas metas produzem como consequência a subsunção de formas de vida, suas práticas e racionalidades, ao mesmo modelo de civilização, como se outro não fosse possível. Por isso, a resistência crítica é tão importante. No comum, na ética da libertação, nos debates descoloniais, novos horizontes são propostos, novas formas de produzir e reproduzir a vida são reveladas.

As distintas perspectivas críticas, ainda que divergindo em inúmeros pontos, convergem, portanto, em permitir o estranhamento de uma realidade que vai sendo naturalizada à medida que avança na construção de sua hegemonia. E diante dessa marcha universalizante, buscou-se contribuir com a apresentação de uma problematização - pretendida desde 
uma perspectiva descolonial, de uma exterioridade crítica, como o aporte trazido pelo debate do comum, definido pela resistência à lógica capitalista universalizante, enquanto possibilidade e necessidade de descolonização do conceito de desenvolvimento e sua consequente abertura - que deve ser permanente, tal como propõe Negri, às racionalidades distintas, permitindo que o distinto sempre exista.

Com precisão, Herrera Flores $(2002$, p. 21) afirmou que "[s]e $a$ universalidade não se impõe, a diferença não se inibe".

\section{REFERÊNCIAS}

AGÊNCIA SENADO. PEC da Felicidade aguarda inclusão na pauta do Plenário. 22 nov. 2011. Disponível em: <https://www12.senado.leg. br/noticias/materias/2011/07/22/pec-da-felicidade-aguarda-inclusao-napauta-do-plenario>. Acesso em 4 mar. 2018.

BARBOSA, Francis Régis Gonçalves Mendes. Índice de Desenvolvimento Relativo, IDH-M e IFDM: em busca da operacionalização das liberdades instrumentais de Amartya Sen. Ensaios FEE, Porto Alegre, v. 38, n. 2, p. 295-328, set. 2017. Disponível em: <https://revistas.fee.tche. br/index.php/ensaios/article/download/3631/3910>. Acesso em 3 mar. 2018.

BUARQUE, Cristóvão. Felicidade e Política. Brasília, maio de 2012. Disponível em: $<$ http://www.senado.gov.br/senadores/senador/ cristova mbuarque/arquivos/ P E C \% $20 \mathrm{da} \% 20$ Felicidade.pdf $>$. Acesso em 4mar. 2018.

CÁRCERES, Florival. História da América. 2 ed. atual. e ampl. São Paulo: Moderna, 1992

DAVID, Colman. Desenvolvimento econômico. 3. Ed. Rio de Janeiro, Campus, 1985.

DARDOT, Pierre; LAVAL, Christian. Comum: ensaio sobre a revolução no século XXI. São Paulo: Boitempo,2017.

DUSSEL, Enrique. Ética da libertação: na idade da globalização e da exclusão. 4. Ed. Rio de Janeiro: Vozes, 2012. 
FERRAZZO, Débora. Pluralismo jurídico e descolonização constitucional na América Latina. 2015. 462 p. Dissertação (Mestrado) - Universidade Federal de Santa Catarina, Centro de Ciências Jurídicas, Programa de PósGraduação em Direito, Florianópolis, 2015.

FURTADO, Celso. Pequena Introdução ao Desenvolvimento. São Paulo: Ed. Nacional, 1980.

GROSFOGUEL, Ramon. Para descolonizar os estudos de economia política e os estudos pós-coloniais: transmodernidade, pensamento de fronteira e colonialidade global. In: SANTOS, Boaventura de Sousa. MENESES, Maria Paula (org). Epistemologias do Sul. São Paulo: 2010. pp. 455-491.

HELLIWELL, John; LAYARD, Richard; SACHS, Jeffrey (ed). World Happiness Report. 2017. Disponível em: < http:// worldhappiness.report/wp-content/uploads/sites/2/2017/03/ HR17.pdf >. Acesso em: 6 mar. 2018.

HERRERA FLORES, Joaquín. Direitos humanos, interculturalidade e racionalidade de resistência. Revista Sequência, Florianópolis, v. 23, n. 44, p. 9-30. 2002. Disponível em: <http://periodicos.ufsc.br/index.php/ sequencia/article/view/15330/13921>. Acesso em: 3 mar. 2018.

INSTITUTO DE PESQUISA DE RELAÇÕES INTERNACIONAIS (IPRI). Fundação Alexandre de Gusmão (FUNAG). As 15 maiores economias do mundo. 21 jun. 2017. Disponível em: $<$ http://www.funag. gov.br/ipri/index.php/o-ipri/47-estatisticas/94-as-15-maiores-economiasdo-mundo-em-pib-e-pib-ppp>. Acesso em 6 mar. 2018.

JESUS OSCAR, Aquino. História das Sociedades Americanas. 7 ed. Rio de Janeiro: Record, 2000.

KRUGMAN, Paul R. Economia Internacional: teoria e política. São Paulo: Pearson Addison Wesley, 2005.

LUDWIG, Celso Luiz.Para uma filosofiajurídica da libertação:paradigmas da filosofia da libertação e direito alternativo. Florianópolis: Conceito Editorial, 2006. 240p.

MOREL, Aline Pereira, et al. Dinheiro não traz felicidade? algumas 
revelações do indicador de Felicidade Interna Bruta. REUNA, Belo Horizonte - MG, Brasil, v.20, n.3, p. 83-108, Jul./Set. 2015. Disponível em: $\quad<$ http://revistas.una.br/index.php/reuna/article/viewFile/680/626>. Acesso em: 6 mar. 2018.

NEGRI, Antonio. Marx, la biopolitica y lo común. Bogotá: Universidad Nacional de Colombia, Instituto Latinoamericano para una Sociedad y un Derecho Alternativos, Victor Manuel Moncayo C. Editor, 2012.

ORGANIZAÇÃO DAS NAÇÕES UNIDAS (ONU). Resolução 65/309, Happiness: towards a holistic approach to development. Resolução adotada na Assembleia Geral de 19 de julho de 2011. Disponível em: $<$ https://undocs.org/A/RES/65/309>. Acesso em 6 mar. 2018.

PROGRAMA PARA DESENVOLVIMENTO DAS NAÇÕES UNIDAS (PNUD) - Brasil. Conceito: $O$ que é desenvolvimento humano? [s.d.]a. Disponível em: <http://www.br. undp.org/content/brazil/pt/home/idh0/conceitos/o-que-edesenvolvimento-humano.html>. Acesso em: 3 mar. 2018.

PROGRAMA PARA DESENVOLVIMENTO DAS NAÇÕES UNIDAS (PNUD) - Brasil.Conceito: o que é IDH?[s.d.] b. Disponível em: $\quad<\mathrm{http}$ :/www.br.undp.org/content/ brazil/pt/home/idh0/conceitos/o-que-e-o-idh.html $>$. Acesso em: 3 mar. 2018.

\section{PROGRAMA PARA DESENVOLVIMENTO DAS NAÇÕES UNIDAS (PNUD) - Brasil.Human Development Report 2016:Human Development for Everyone. Disponível em: <http://www. br.undp.org/content/dam/brazil/docs/RelatoriosDesenvolvimen to/undp-br-2016-human-development-report-2017.pdf >. Acesso em 3 mar. 2018.}

RUSCHEL, Caroline Vieira. Os limites do Direito Ambiental na preservação dos recursos naturais comuns: epistemologia da sustentabilidade e estudos de caso. Tese (Doutorado em Direito). Programa de Pós-Graduação em Direito da Universidade Federal de Santa Catarina. 2018.

SALES et al. Felicidade interna bruta: aplicação e discussão no contexto de cidades de porte médio brasileiras. Revista 
$C A D E$, v. 12, n. 1. Disponível em: <http://editorarevistas. mackenzie.br/index.php/cade/article/download/6330/4483>. Acesso em 3 mar. 2018.

SEN, Amartya. Desenvolvimento como liberdade. São Paulo: Cia das Letras, 2000.

SEN, Amartya. A ideia de justiça. São Paulo: Companhia das Letras, 2011.

SIEDENBERG, Dieter Rugard. Indicadores de desenvolvimento socioeconômico: uma síntese. Editora Unijuí, ano 1, n. 1, jan./ jun. 2003, p. 45-71. Disponível em: <https://www.revistas. unijui.edu.br/index.php/desenvolvimentoemquestao/article/view/67/24>. Acesso em 3 mar. 2018.

TOJAL, Altamir (Associação Brasileira de Imprensa - ABI). Governo e Movimentos Sociais. 23 dez. 2008. Disponível em: $<$ http://www.abi.org. br/governo-e-movimentos-sociais/>. Acesso em 31 mar. 2018.

WOLKMER, Antonio Carlos. Introdução ao pensamento jurídico crítico. 8 ed. São Paulo: Saraiva, 2012.

WOLKMER, Antonio Carlos. História do direito no Brasil. 2. ed. Rio de Janeiro: Forense, 1999.

WOLKMER, Antonio Carlos. Fundamentos de história do direito. 3. ed. rev. e ampl. Belo Horizonte: Del Rey, 2005.

ZEA, Leopoldo. Discurso desde a marginalização e a barbárie; seguido de A filosofia latino-americana como filosofia pura e simplesmente. Rio de Janeiro: Garamond, 2005. 488p.

\section{Como citar este artigo (ABNT):}

WOLKMER, Maria de Fatima Schumacher; FERRAZZO, Débora. O PARADOXO DO DESENVOLVIMENTO: DIREITO AMBIENTAL E BENS COMUNS NO CAPITALISMO. Veredas do Direito, Belo Horizonte, v. 15, n. 33, p. 163-189, set./dez. 2018. Disponível em: <http:// www.domhelder.edu.br/revista/index.php/veredas/article/view/1269>. Acesso em: dia mês. ano.

Artigo recebido em: 04/04/2018

Artigo aceito em: 20/11/2018 